\title{
Redundant Operation of a Parallel AC to DC Converter via a Serial Communication Bus
}

\author{
Yutthana Kanthaphayao*, Uthen Kamnarn**, and Viboon Chunkag ${ }^{\dagger}$ \\ $\dagger *$ Dept. of Electrical Eng., King Mongkut's University of Technology North Bangkok, Bangkok, Thailand \\ ** Dept. of Electrical Eng., Rajamangala University of Technology Lanna, Chiang Mai, Thailand
}

\begin{abstract}
The redundant operation of a parallel AC to DC converter via a serial communication bus is presented. The proposed system consists of three isolated CUK power factor correction modules. The controller for each converter is a dsPIC30F6010 microcontroller while a RS485 communication bus and the clock signal are used for synchronizing the data communication. The control strategy of the redundant operation relies on the communication of information among each of the modules, which communicate via a RS485 serial bus. This information is received from the communication checks of the converter module connected to the system to share the load current. Performance evaluations were conducted through experimentation on a threemodule parallel-connected prototype, with a $578 \mathrm{~W}$ load and a $-48 \mathrm{~V}$ dc output voltage. The proposed system has achieved the following: the current sharing is quite good, both the transient response and the steady state. The converter modules can perform the current sharing immediately, when a fault is found in another converter module. In addition, the transient response occurs in the system, and the output voltages are at their minimum overshoot and undershoot. Finally, the proposed system has a relatively simple implementation for the redundant operation.
\end{abstract}

Key Words: Parallel AC to DC Converter, Redundant Operation, Serial Communication Bus

\section{INTRODUCTION}

A redundant converter module for the front-end $\mathrm{AC}$ to DC converter in a distributed power system (DPS) has been purposed for increasing system reliability and flexibility while supplying a continuous load, etc [1]. This redundant system is used in systems which require a higher reliability such as telecommunication systems, air traffic control systems, and medical equipment. Usually, a redundant system is composed of a number of converter modules which must exceed the maximum required power, such as $(M+1)$ where $M$ is the minimum number of modules required to supply of the maximum amount of power, and 1 is the redundant module [1]-[4].

According to the control schemes of the parallel-connected converter module in a DPS, the controllers have been described as follows. The droop method has been explained in [5]. This method is achieved based on system modularity and flexibility. There is no communication link among the other controllers of each converter module. Thus, it has some drawback for example, the current sharing and the output voltage regulation are quite poor and they have a slow transient response. Active current sharing schemes, such as centralized control

\footnotetext{
Manuscript received Sep. 23, 2010; revised Apr. 18, 2011

Recommended for publication by Associate Editor Yong-Chae Jung.

$\dagger$ Corresponding Author: vck@kmutnb.ac.th

Tel: +66-2-5874351, King Mongkut's Univ. of Tech., North Bangkok

* Dept. of Electrical Eng., King Mongkut's University of Technology, North Bangkok, Thailand

** Dept. of Electrical Eng., Rajamangala University of Technology, Lanna, Thailand
}

and master-slave control, are introduced in [6] and [7], [8], respectively. These methods achieve a tight output voltage and good current sharing. However, these methods decreased system reliability, modularity and system flexibility.

In addition, the distributed control methods in [9]-[11] possess the following structure: an individual controller with an external communication link among the others. For data communication, the information obtained from the communication can be used for power system management, monitoring of the system and current sharing, [12]-[15] etc. Therefore, in these controllers, there are several advantages such as increase system reliability and flexibility. For this reason, this paper employs the distributed control of parallel AC to DC converters.

The wire line of a communication-link connects between the controllers of each converter module. This communication link is used for sharing the bus of the current command or the voltage reference. Both an analog circuit [16] and a digital bus [12]-[15] can be used. There are several advantages to using a digital bus implementation instead of an analog circuit, such as noise immunity, higher reliability, and complex control algorithms. For these reasons, this paper employs a digital communication bus via a RS485 serial bus to communicate between the other controllers.

The RS485 communication bus and the clock signal (CLS) for bus synchronizing are employed in redundant operation and they check the number of the converter module in the system for the current sharing. The voltage control loop of 
TABLE I

THE PARAMETERS OF THE PROPOSED SYSTEM

\begin{tabular}{|l|l|}
\hline Characteristics & Values \\
\hline Input power source & $220 \mathrm{~V}, 50 \mathrm{~Hz}$ \\
\hline Rated Power & $250 \mathrm{~W} /$ module \\
\hline Output voltage & $-48 \mathrm{~V}$ \\
\hline Input inductor: $L_{11}, L_{12}, L_{13}$ & $5.0502 \mathrm{mH}, 5.0822 \mathrm{mH} 4.9900 \mathrm{mH}$ \\
\hline Output inductor: $L_{21}, L_{22}, L_{23}$ & $1.0627 \mathrm{mH}, 1.0805 \mathrm{mH} 1.0227 \mathrm{mH}$ \\
\hline$C_{a 1}, C_{b 1}, C_{a 2}, C_{b 2}, C_{a 3}, C_{b 3}$ & $0.68 \mu \mathrm{F}$ \\
\hline Output Capacitor, $C_{O}$ & $20,400 \mu \mathrm{F}$ \\
\hline transformer ratio $(a)$ & 0.5 \\
\hline Output voltage gain $\left(G_{T V}\right)$ & $1 / 12$ \\
\hline Load current gain $\left(G_{T I}\right)$ & 3.33 \\
\hline
\end{tabular}

each converter module is compensated by the fuzzy gain scheduling of a PI (FGPI) controller. In order to obtain a fast transient response, a voltage control signal is added by a signal from the power balance control technique. After the introduction, this paper presents the details of the proposed system in Section II, follow by the controller design for the proposed system in Section III. Experimental results including the transient response, the redundant operation and the system operated in the steady-state are indicated in Section IV. Finally, Section $\mathrm{V}$ provides the conclusion.

\section{The Proposed SYSTEM}

The parallel AC to DC converter shows in Fig. 1 consists of three converters. Converter modules \#1 and \#2 feed power to the load and converter module \#3 acts as a redundant module. Each converter is an isolated CUK AC to DC converter and has its own individual controller, as presented in Fig. 2. The control strategy of the distributed control is composed of the following structure: a RS485 communication bus link among the controllers and a clock signal for synchronizing the transmitting or receiving data. For a clear illustration, the parameter values for the proposed system are shown in Table I.

\section{The Controller Design of the Proposed SYSTEM}

\section{A. The dsPIC30F6010 Microcontroller [17]}

The peripherals are used for implementation on the distributed control, including the ADC, UART, SPI, INT1, INT2 and Timer1 modules. The ADC module converts the continuous signal $\left(v_{o}, i_{o}, V_{r m s}\right.$, and $\left.\left|v_{s}\right|\right)$ into a digital signal at 4 $\mathrm{kHz}$ of the sampling rate. The UART module is used for transmitting or receiving data communication with a baud rate of $115200 \mathrm{bps}$. The SPI module is used for transmitting the control signal to a digital to analog converter (DAC). The INT1 module (external interrupt) employs the synchronization of the time slot for transmitting or receiving data between the various microcontrollers. The INT2 module (external interrupt) is used for receiving the fault signal. Finally, the Timer1 module is used for updating the control signal at $4 \mathrm{kHz}$.

Fig. 3 (a) presents a flowchart of the main program implemented on the proposed system. Fig. 3 (b) shows the procedure for generating a current command $\left(i_{\text {Lref }}(k)\right)$ to control the input current of each converter module.
TABLE II

MESSAGE FORMAT OF THE COMMUNICATION PROTOCOL

\begin{tabular}{|c|l|}
\hline Contents & Description \\
\hline : & Start of communication \\
\hline a, b, c & Address of module \#1, \#2, \#3 \\
\hline 0x0d & End of communication \\
\hline
\end{tabular}

\section{B. The Serial Communication Bus}

A universal asynchronous transmitter/receiver (UART) employs the data communication between the various microcontrollers via a RS485 serial bus. In this communication protocol, the message format is employed. It consists of 3 parts; the start of communication, the address of the converter module, and the end of communication as shown in Table II.

Data communication enables the system to check the number of the converter modules $(N)$ which are parallel-connected in the system. The $N$ is used for sharing the load current of each converter module.

Fig. 4 shows an example of the data communication between the controllers of all of the converter modules. Fig. 4 (a) illustrates a flowchart of the data transmission of converter module \#1. Fig. 4 (b) presents the data receiving method to update the number of the converter modules which are connected to the system. In the time slot for synchronizing the communication, the controller counts the rising edge of the CLS at the INT1 interrupt when $n$ denotes the number of the CLS. In the case where $n$ equals 1 , the UART of controller \#1 sends data to the other controllers via the RS485 serial bus. Similarly, if $n$ is equal to 4 and 7, then the UART of controllers \#2 and \#3 enter the data sending mode. One cycle of the time slot is composed of 10 clock pulses (0-9). The enable signal of each controller is defined by using port RB10 for receiving and sending data. If the enable signal is set to a high logic level, the controller enters the data sending mode. To illustrate the proposed method, Fig. 5 indicates the signal of the CLS, the signal on the digital bus, and an enable signal for receiving and sending the data of each controller.

\section{The Fuzzy Gain Scheduling of a PI Controller}

The power conversion circuits to supply a load are inherent nonlinear plants such as an AC to DC converter, a DC to DC converter or a $\mathrm{DC}$ to $\mathrm{AC}$ converter. According to this plant, the mathematic model and the control design are complicated for the design procedure because of parameter uncertainty in the system. This effects the change of the operating point of the system. To solve this problem, the controllers presented in [18]-[24] can be used to control a nonlinear system. In this paper, we focus on the technique of fuzzy gain scheduling of a PI controller [20] to control the system, due to its ease of implementation. Fig. 6 shows a block diagram of the output voltage control. In this controller, the main controller of the output voltage is a PI controller but the parameters $K_{P}$ and $K_{I}$ are adjusted by fuzzy rules. The input of fuzzy rules and reasoning are based on the output error $(e(k))$ and the change in error $(\Delta e(k))$ to determine the PI controller gains. The membership function of the output error and the change in error are shown in Fig. 7. These fuzzy sets include: NB negative big, NM negative medium, NS negative small, ZE 


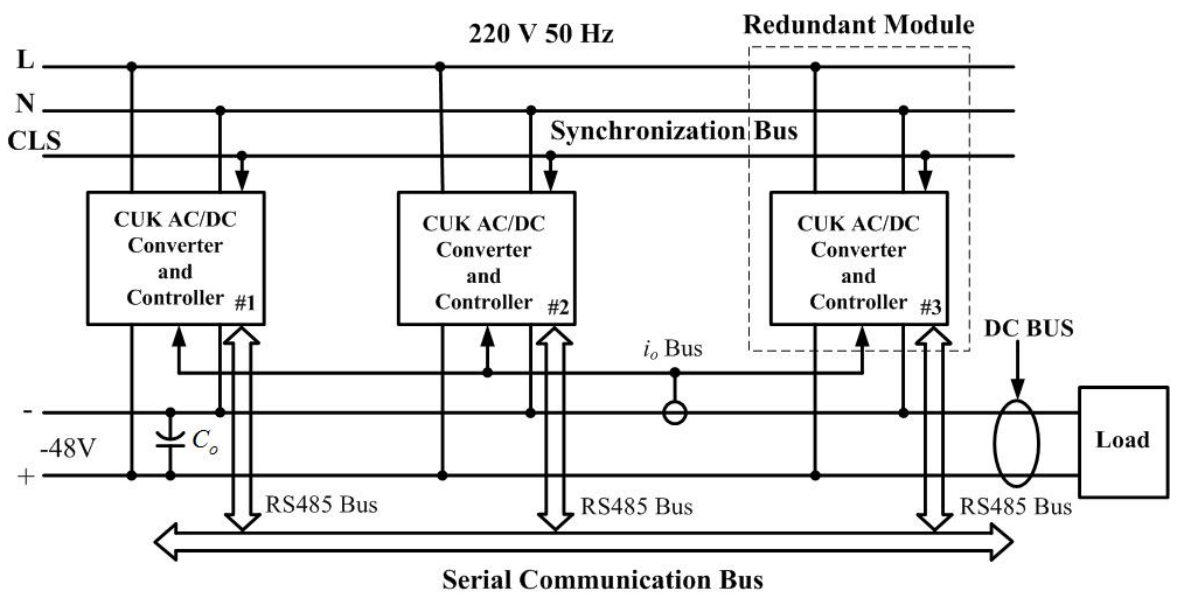

Fig. 1. Parallel AC to DC converter.

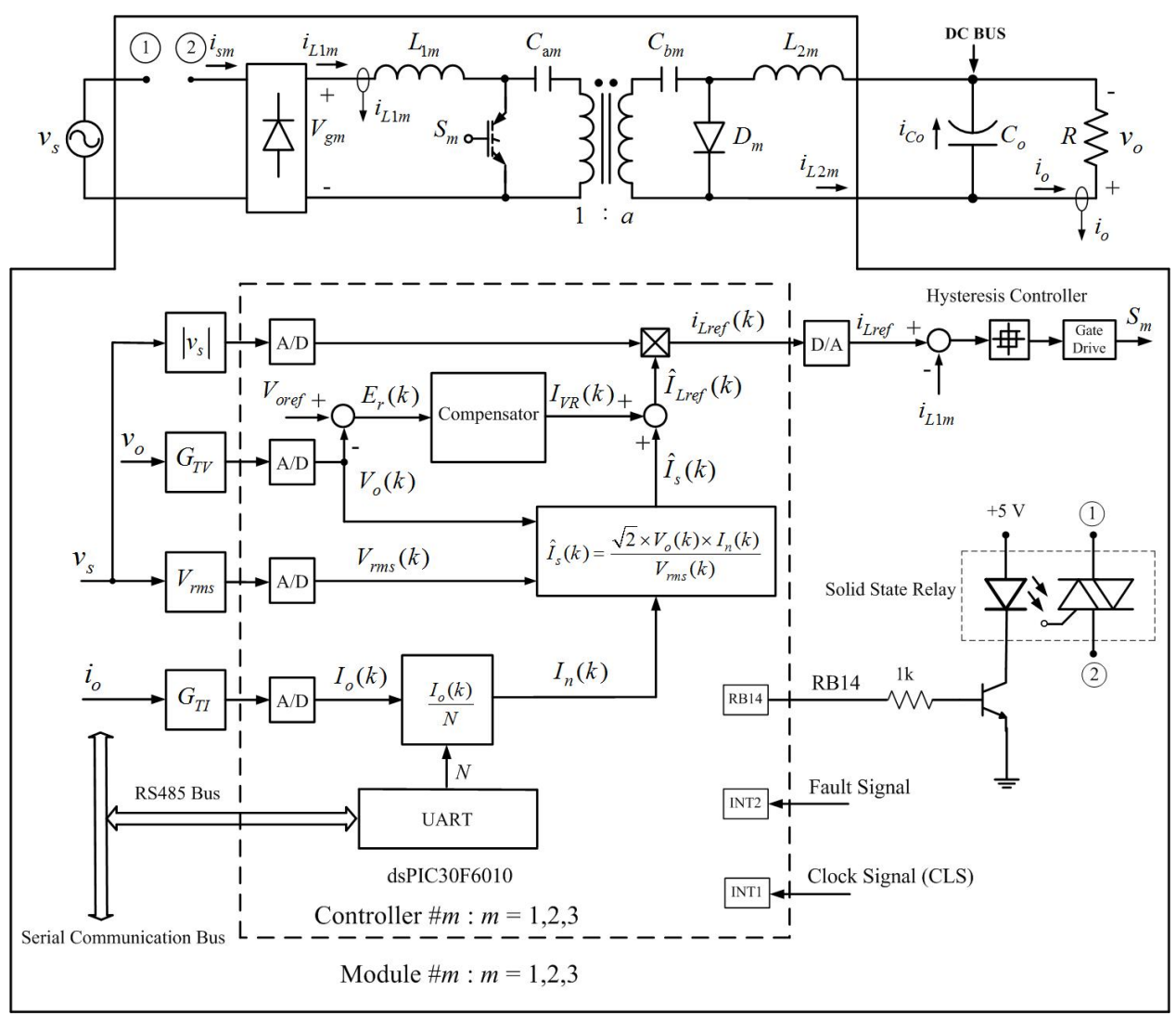

Fig. 2. Power circuit and controller of each converter module.

zero equal, PS positive small, PM positive medium, and PB positive big. The proposed system will be satisfied with a fast transient response, an output voltage with the minimum overshoot and undershoot, and tight output voltage regulation.

For the parameters of the PI controller, the assumptions $K_{P}$ and $K_{I}$ are in the prescribed ranges $\left[K_{P(\min )}, K_{P(\max )}\right]$ and $\left[K_{I(\min )}, K_{I(\max )}\right]$. For convenience, $K_{P}$ and $K_{I}$ are normalized into a range between zero and one by the following linear transformation [20], as Eq. (1) and (2).

$$
\begin{aligned}
K_{P}^{\prime} & =\left(K_{P}-K_{P(\min )}\right) /\left(K_{P(\max )}-K_{P(\min )}\right) \\
K_{I}^{\prime} & =\left(K_{I}-K_{I(\min )}\right) /\left(K_{I(\max )}-K_{I(\min )}\right)
\end{aligned}
$$

The parameters $K_{P}^{\prime}$ and $K_{I}^{\prime}$ are determined by a set of fuzzy IF-THEN rules, from the following:

$$
\begin{aligned}
& \text { If } e(k) \text { is } A_{i} \text { and } \Delta e(k) \text { is } B_{i} \text {, then } K_{P}^{\prime} \text { is } C_{i} \text { and } K_{I}^{\prime} \text { is } D_{i} \\
& \qquad i=1,2, \ldots, m .
\end{aligned}
$$

where $A_{i}$ and $B_{i}$ are the fuzzy sets or the condition cases, and $C_{i}$ and $D_{i}$ are the operation cases, which can be either big (B) or small (S). The membership functions of $K_{P}^{\prime}$ and $K_{I}^{\prime}$ are shown in Fig. 8 which is used for considering the operation case. A rule base of fuzzy gain scheduling is considered from the step response of the system. For example, in the condition of the transient response, the gain of $K_{P}^{\prime}$ should be as big to 


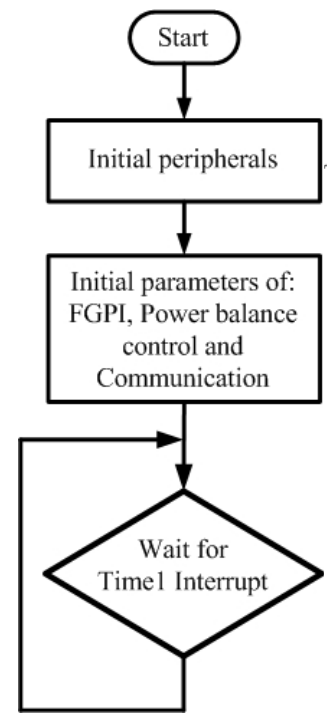

(a) Main program.

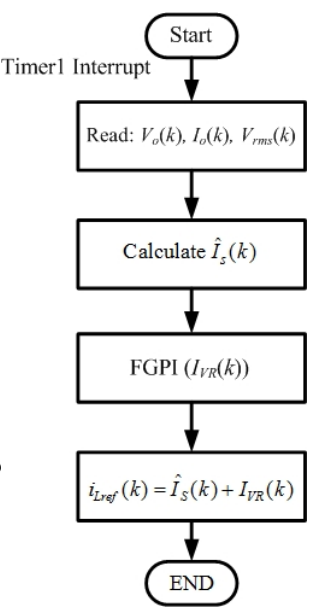

(b) Update current command.

Fig. 3. Flowchart of the controller of each converter module.

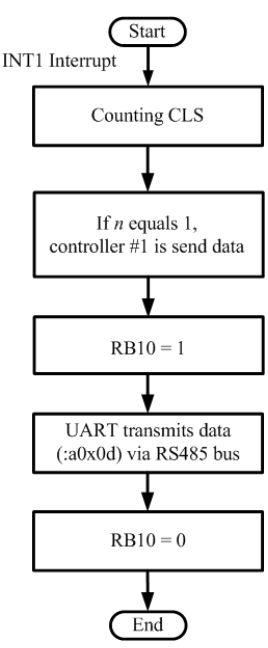

(a)

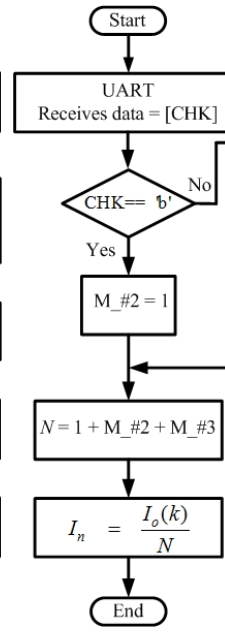

(b)
Fig. 4. Flowchart of the controller \#1 while the data communication among the other controller. (a) Send data. (b) Update the number of the converter module is connected in the system.

improve the transient response, but the gain of $K_{I}^{\prime}$ is small to prevent an overshoot. In case of the steady-state, to eliminate the steady-state error, the gain of $K_{I}^{\prime}$ is big and the gain of $K_{P}^{\prime}$ is small to reduce the system oscillations. Thus, the operation case for the parameters of $K_{P}^{\prime}$ and $K_{I}^{\prime}$ are shown in Table III and IV.

The step by step equation for fuzzy gain scheduling to adapt the parameters $K_{P}$ and $K_{I}$ can be summarized as follows [20].

1) Calculate the output error and the change of error as:

$$
\begin{aligned}
e(k) & =V_{\text {oref }}-V_{o}(k) \\
\Delta e(k) & =e(k)-e(k-1) .
\end{aligned}
$$

2) Evaluate the membership functions of the output error and the change of error, as indicated in Fig. 7.

3 ) The membership functions of the output error and the change of error are applied in Eq. (6) for implicating the
TABLE III

FUZZY RULES OF $K_{P}^{\prime}$

\begin{tabular}{|c|c|c|c|c|c|c|c|}
\hline$e^{\Delta(k)}{ }^{\Delta e(k)}$ & NB & NM & NS & ZE & PS & PM & PB \\
\hline NB & B & B & B & B & B & B & B \\
\hline NM & S & B & B & B & B & B & S \\
\hline NS & S & S & B & B & B & S & S \\
\hline ZE & S & S & S & S & S & S & S \\
\hline PS & S & S & B & B & B & S & S \\
\hline PM & S & B & B & B & B & B & S \\
\hline PB & B & B & B & B & B & B & B \\
\hline
\end{tabular}

TABLE IV

\begin{tabular}{|c|c|c|c|c|c|c|c|}
\hline$\Delta e(k)$ & $\mathrm{NB}$ & $\mathrm{NM}$ & NS & $\mathrm{ZE}$ & PS & PM & $\mathrm{PB}$ \\
\hline NB & $\mathrm{S}$ & $S$ & $S$ & $\mathrm{~S}$ & $\mathrm{~S}$ & $\mathrm{~S}$ & $\mathrm{~S}$ \\
\hline NM & $S$ & S & $\mathrm{B}$ & $\mathrm{B}$ & $B$ & $\mathrm{~S}$ & $\mathrm{~S}$ \\
\hline NS & $S$ & B & B & B & B & B & $\mathrm{S}$ \\
\hline $\mathrm{ZE}$ & B & B & B & B & B & B & B \\
\hline PS & $S$ & B & B & B & B & B & $\mathrm{S}$ \\
\hline PM & $\mathrm{S}$ & $\mathrm{S}$ & $\mathrm{B}$ & $\mathrm{B}$ & $\mathrm{B}$ & $\mathrm{S}$ & $\mathrm{S}$ \\
\hline $\mathrm{PB}$ & $\mathrm{S}$ & $S$ & $\mathrm{~S}$ & $\mathrm{~S}$ & $S$ & $\mathrm{~S}$ & $S$ \\
\hline
\end{tabular}

FUZZY RULES OF $K_{I}^{\prime}$

process of the fuzzy rules.

$$
\mu_{i}=\mu_{i}[e(k)] \bullet \mu_{i}[\Delta e(k)]
$$

4) When, we get the membership function $\mu_{i}$ which is related to adapt the parameters $K_{P}^{\prime}$ and $K_{I}^{\prime}$, the parameters $K_{P}^{\prime}$ or $K_{I}^{\prime}$ from Fig. 8 can be found.

5) According to the membership function, as shown in Fig. 8 , the defuzzication method can be seen as:

$$
\sum_{i=1}^{m} \mu_{i}=1
$$

Then, the parameters $K_{P}^{\prime}$ and $K_{I}^{\prime}$ are calculated from:

$$
\begin{aligned}
K_{P}^{\prime} & =\sum_{i=1}^{m} \mu_{i} K_{P, i} \\
K_{I}^{\prime} & =\sum_{i=1}^{m} \mu_{i} K_{I, i} .
\end{aligned}
$$

6) Calculate the parameters $K_{P}$ and $K_{I}$ as in the follows:

$$
\begin{aligned}
K_{P} & =\left(K_{P(\max )}-K_{P(\min )}\right) K_{P}^{\prime}+K_{P(\min )} \\
K_{I} & =\left(K_{I(\max )}-K_{I(\min )}\right) K_{I}^{\prime}+K_{I(\min )} .
\end{aligned}
$$

D. The Consideration of the Prescribed Ranges $\left[K_{P(\min )}\right.$, $\left.K_{P(\max )}\right]$ and $\left[K_{I(\min )}, K_{I(\max )}\right]$

In the considerate method, the parameters of $\left[K_{P(\min )}\right.$, $\left.K_{P(\max )}\right]$ and $\left[K_{I(\min )}, K_{I(\max )}\right]$, trial and error or empirically [22] are employed. The system exhibits a fast transient response, and the output voltage has a minimum overshoot and undershoot when there is a disturbance.

\section{E. The Power Balance Control Technique}

The systems in [25], [26], offer a fast transient response because power balance control techniques were applied in the voltage control loop. The power balance was considered at the AC input power source of the converter and the DC bus of the output voltage. In order to obtain input current sharing, the load current will be shared by the number of converter 


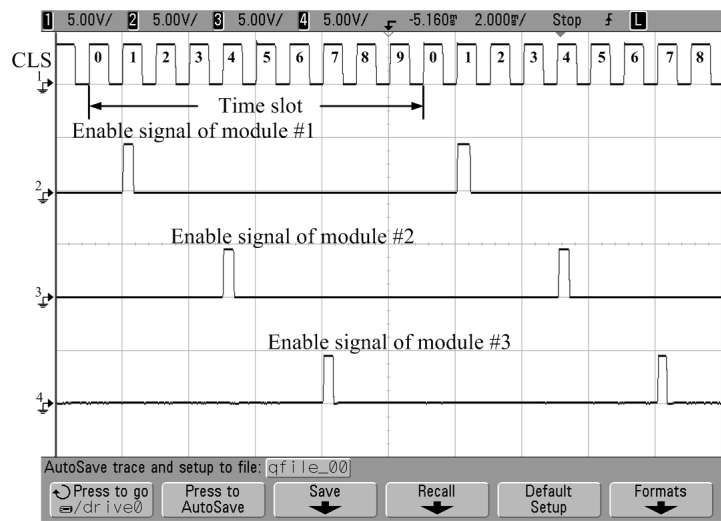

(a) The clock signal (CLS) and enable signal to send or receive data of each controller.

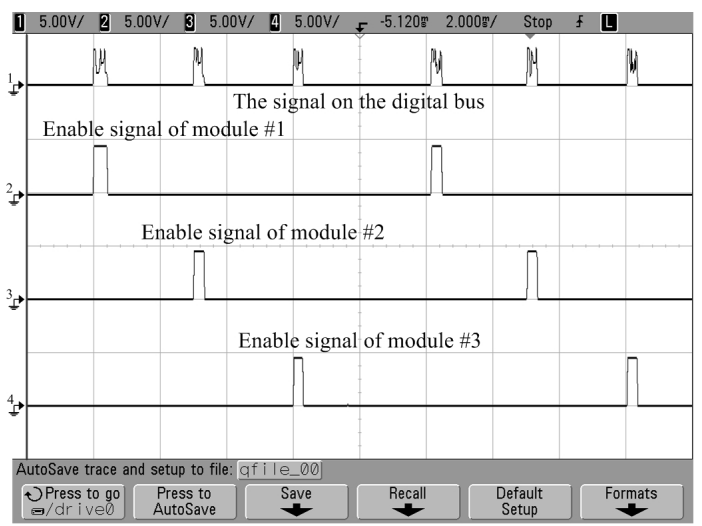

(b) The signal on the digital bus and enable signal to send or receive data of each controller.

Fig. 5. The data communication among the controller of each converter module.

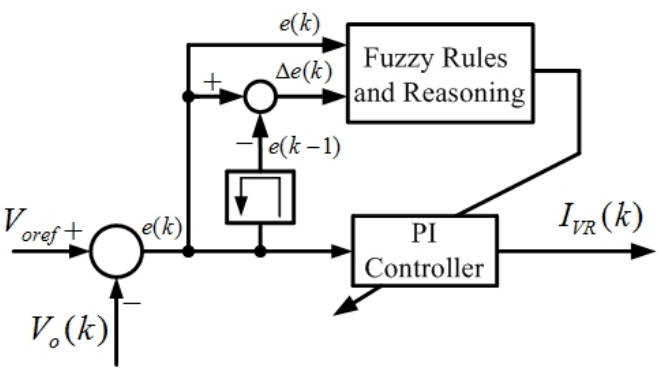

Fig. 6. Fuzzy gain scheduling of PI controller.

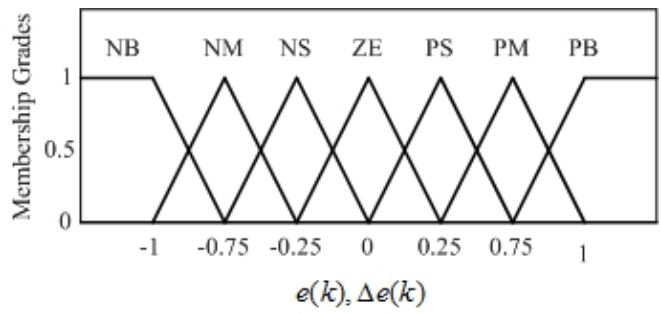

Fig. 7. Membership function of error and change of error.

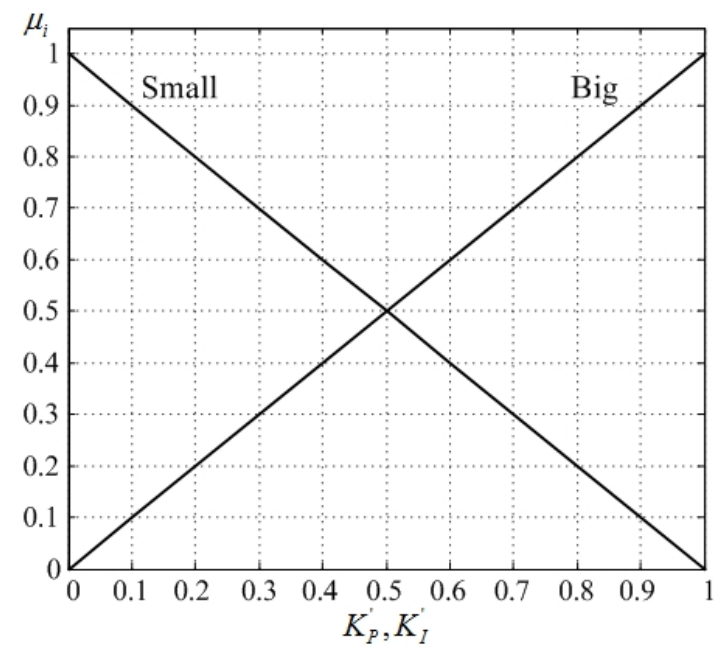

Fig. 8. Membership function of $K_{P}^{\prime}$ and $K_{I}^{\prime}$. modules $(N)$. The number of converter modules is obtained from information via the RS485 serial communication bus. From Fig. 2, if the input inductor currents are equal to the individual input current $\left(I_{s}(k)\right)$, the power balance of the individual converter modules can be indicated by:

$$
\begin{gathered}
V_{r m s}(k) I_{s}(k)=V_{o}(k) \frac{I_{o}(k)}{N} \\
I_{s}(k)=\frac{V_{o}(k) I_{o}(k)}{N V_{r m s}(k)} \\
\hat{I}_{s}(k)=\frac{\sqrt{2} V_{o}(k) I_{o}(k)}{N V_{r m s}(k)} . \\
i_{\text {Lref }}(k)=\hat{I}_{s}(k)+I_{V R}(k)
\end{gathered}
$$

where $\hat{I}_{s}(k)$ is the peak input current. In Fig. 2, the dsPIC30F6010 microcontroller is indicated by the dashed outline. The peak input current, $\hat{I}_{s}(k)$ is added to the signal from the fuzzy gain scheduling of the PI controller $\left(I_{V R}(k)\right)$ as indicated in Eq. (14). Then, the signal is multiplied by the absolute sinusoidal waveform. As a result, the current command $\left(i_{\text {Lref }}(k)\right)$ to control the input current of the converter module is obtained. Furthermore, the current command is converted by the DAC to control the input current. In the current control loop, a hysteresis controller circuit is employed in the proposed system due to its ease of implementation.

\section{F. The Control Method of the Redundant Operation}

If a single converter module experiences a fault, it informs the other modules, suddenly. Then, the remainder of the converter modules will be started for sharing the load current, immediately. To sum up, the redundant operation control of the system is performed by the digital communication bus via a RS485 serial bus to communicate with the other controllers. This method is easily to implementation and it will be verified below. 


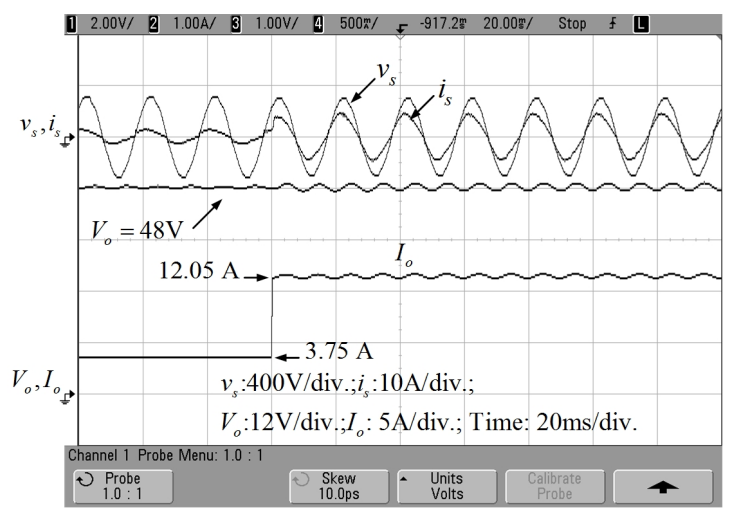

(a) The load current increase from 3.75 to $12.05 \mathrm{~A}$.

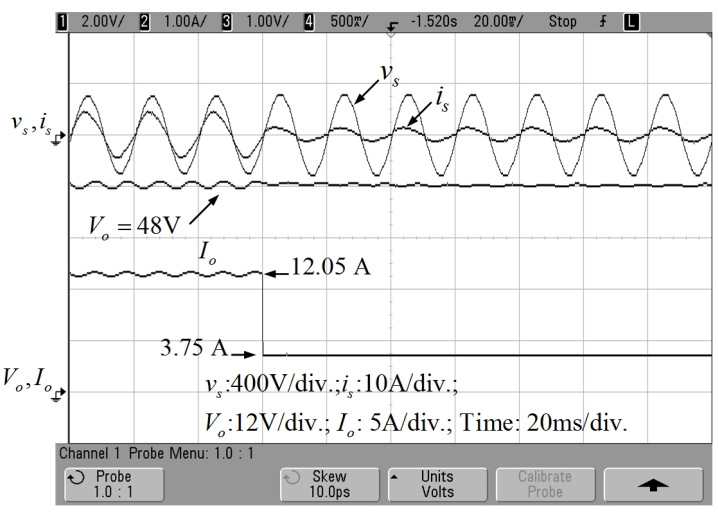

(b) The load current decrease from 12.05 to $3.75 \mathrm{~A}$.

Fig. 9. Waveforms of the input voltage and current, the output voltage and current occurs the transient response.

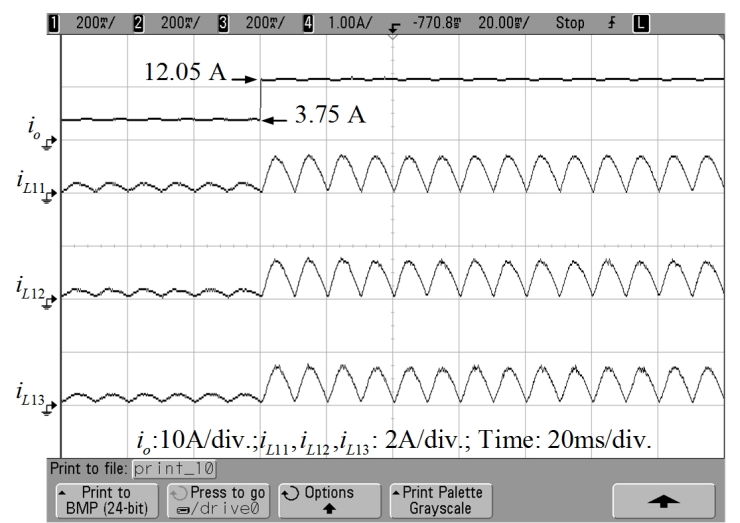

(a) The load current increase from 3.75 to $12.05 \mathrm{~A}$.

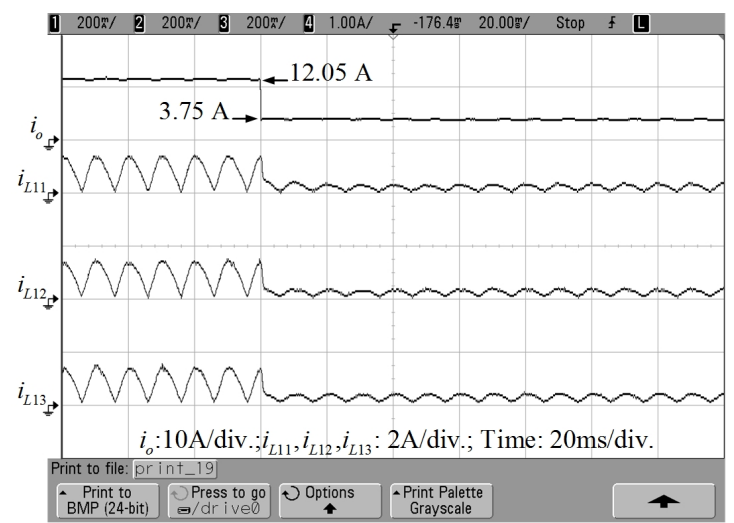

(b) The load current decrease from 12.05 to $3.75 \mathrm{~A}$.

Fig. 10. Waveform of the load current and the individual.

\section{EXPERIMENTAL RESULTS}

The proposed system was constructed and tested on three isolated CUK power factor correction circuits. The parameters of the isolated CUK converters are shown in Table I. The output voltage and the load current throughout the experiment show invert polarity.

\section{A. The Transient Responses of the Proposed System}

Fig. 9 shows the transient response of the system when changing the load current from 3.75 to $12.05 \mathrm{~A}$ and then back to 3.75A. The waveforms at the input AC power source of the converter, the output voltage, and the load current are shown in Fig. 9 (a) and (b). It can be seen that the system achieves a fast transient response. The settling time to the steady state is very fast and the output voltage achieves a minimum overshoot and undershoot. The input current is nearly sinusoidal and in-phase with the input voltage so the harmonic distortion at the input AC power source of the converter is also low. Fig. 10 shows the transient response of the individual input inductor current. As a result, the current sharing of each converter module is quite good.

\section{B. Redundant Operation}

1) Three Modules Operate in the System: In this redundant operation, there are three modules operating in the system.

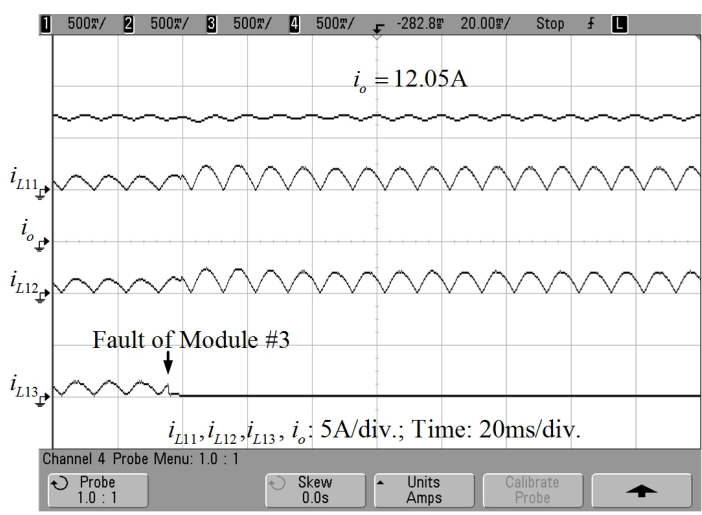

Fig. 11. The individual input inductor current and the load current.

In the case of a single converter module fault, for instance converter module \#3, the remaining converter modules will be started for sharing the load current, immediately. Fig. 11 shows the waveforms of the individual input inductor current and the load current. $i_{L 11}, i_{L 12}$ and $i_{L 13}$ are the input inductor currents of modules \#1, \#2 and \#3, respectively. Fig. 12 presents the waveforms of the individual input inductor current and the output voltage. The input current of the system is indicated in Fig. 13.

From the experimental results, it can be seen that the proposed control method can be operated in the redundant mode. According to the experiment, the system achieves a 


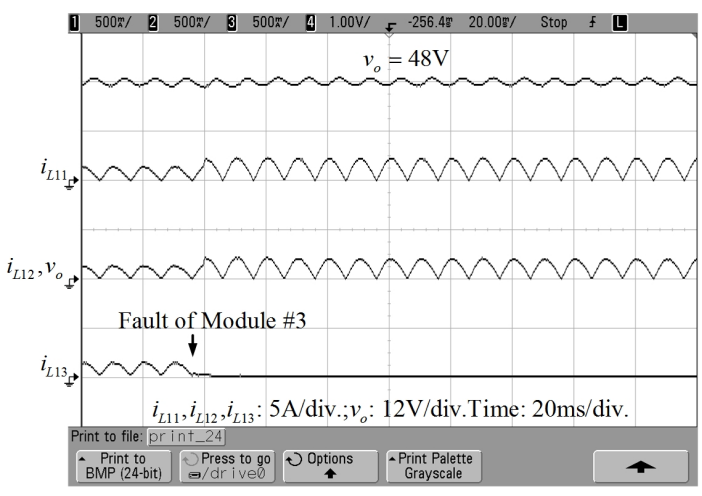

Fig. 12. The individual input inductor current and the output voltage.

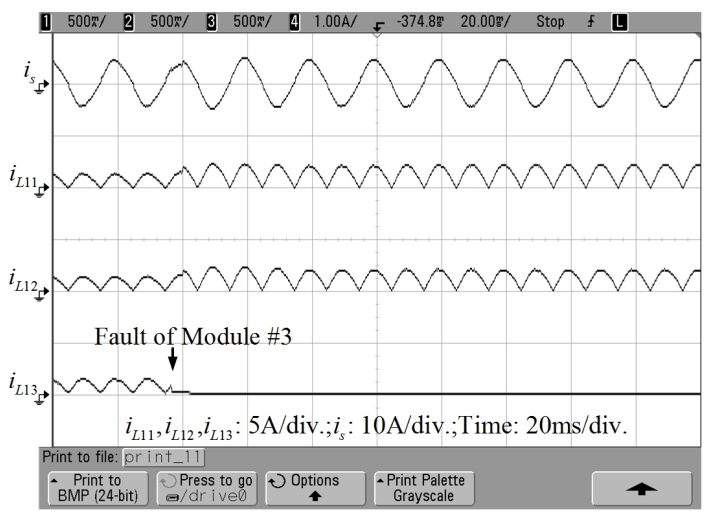

Fig. 13. The individual input inductor current and the input current.

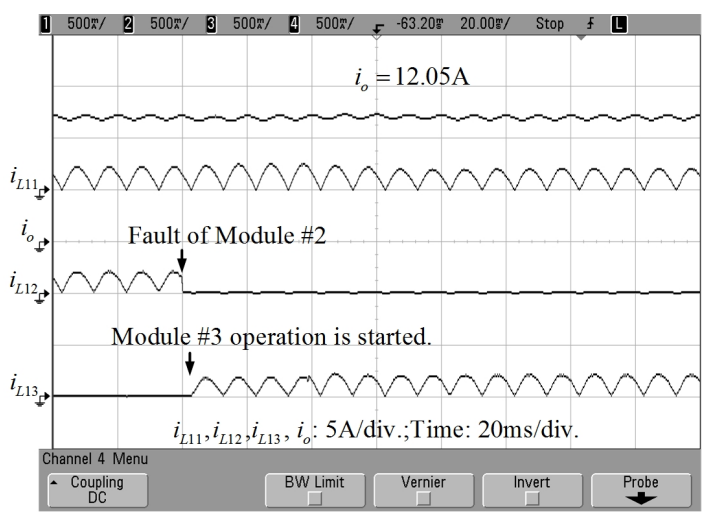

Fig. 14. The individual input inductor current and the load current.

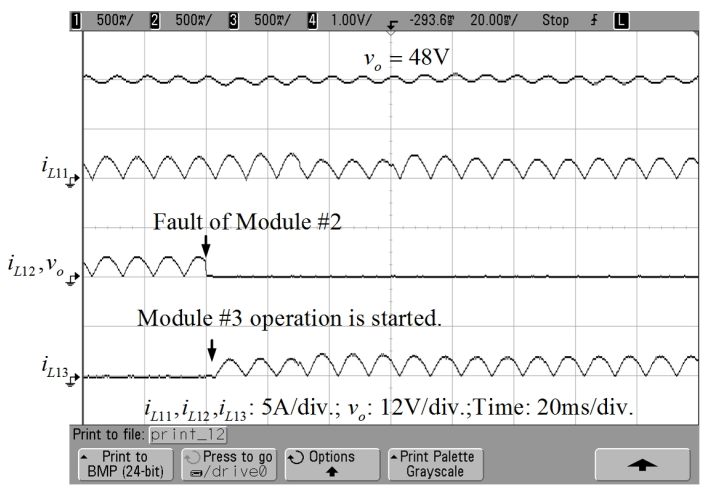

Fig. 15. The individual input inductor current and the output valtage.

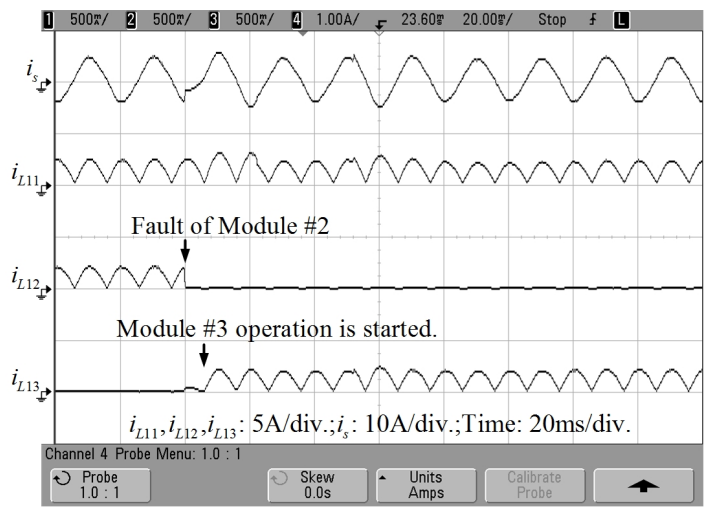

Fig. 16. The individual input inductor current and the input current.

fast response time when a converter module is lost from the system. Therefore, the system can be supplied with a continuous load.

2) Two Modules Operate in the System: Under this condition, the two converter modules are operated to supply an output power. In the case of a single converter module fault, for instance converter module \#2, converter module \#3 will suddenly be inserted into the system. As a result, the waveforms are as follows. Fig. 14 shows the waveforms of the individual input inductor current and the load current.

Fig. 15 shows the individual input inductor current and the output voltage while the individual input inductor current and the input current are shown in Fig. 16. It can be seen from the waveforms in Fig. 14 to 16 that, the system can supply a continuous load even through converter module \#2 experiences a fault in the system. In addition, it can be seen that, the output voltages have been achieved at a minimum overshoot and undershoot and that the settling time of the response is very small.

The experimental results of the redundant operation are presented. It can be seen that the information is communicated among the controllers of each converter module via a RS485 serial bus with a baud rate of $115200 \mathrm{bps}$ and that the controllers of each converter can recognize the addresses of the other modules when the converter module is disconnected or connected into the system, immediately. The addresses of the other converter modules are used for checking the number of converters for load current sharing. To sum up, the data communication with a baud rate of 115200 bps satisfies the requirement of the redundant operation of a parallel-connected $\mathrm{AC}$ to $\mathrm{DC}$ converter.

\section{The System is Operated in the Steady-State}

Fig. 17 shows the output voltage ripple at the load current $12.05 \mathrm{~A}(578 \mathrm{~W})$, which is $1.8 \mathrm{~V}$. The power quality at the input AC power source of the converter is presented in Fig. 18. As can be seen from the experimental results, the measured power factor and the total harmonic distortion were conducted by the digital power meter model 2531A and they were 0.98 and $6.77 \%$, respectively. Fig. 19 shows the power factor at a difference input voltage while the load was varied from a light load to a full load. Obviously, the overall system nearly achieves a unity power factor, especially, when the load is 


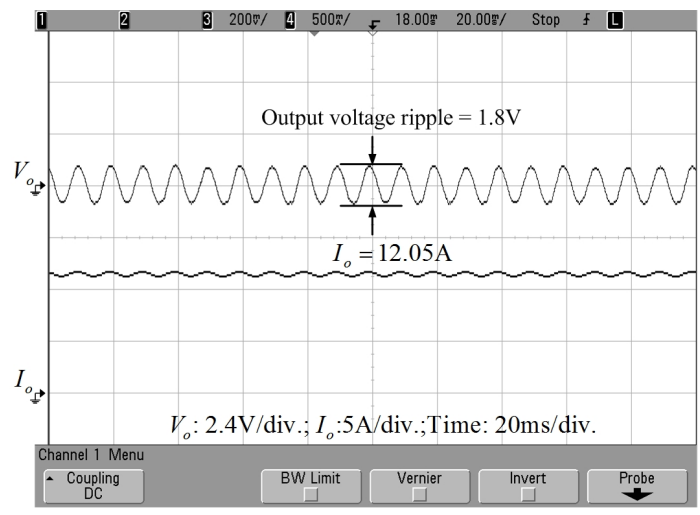

Fig. 17. Waveform of the output voltage ripple at a $578 \mathrm{~W}$ load.

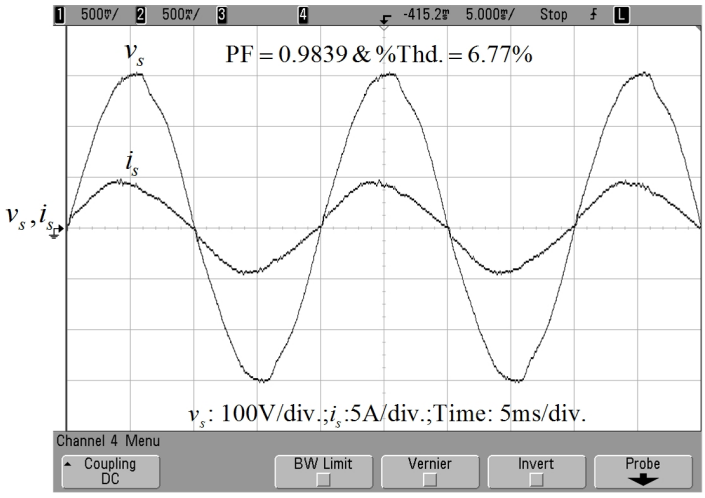

Fig. 18. Waveforms of the input voltage and current at a $578 \mathrm{~W}$ load.

near a full load. Fig. 20 shows the harmonic distortion at the input AC power source versus the different load. Apparently the harmonic distortion complies with the IEC 61000-3-2 class A limit.

\section{CONCLusions}

The redundant operation of a parallel AC to DC converter is presented. The control strategy for the redundant operation is by means of communicated information between the other controllers. Moreover, the load sharing of each converter module is achieved without an extra controller because it employs information obtained from each module and communicated with the other modules via a RS485 serial bus. A performance evaluation was conducted through experimentation on three modules parallel-connected, with a $578 \mathrm{~W}$ load, $-48 \mathrm{~V}$ dc output voltage. The proposed system has achieved the following. Firstly, the current sharing is quite good in both the transient response and the steady state. Also, the converter module enables the current sharing immediately whenever a fault if found in the other converter modules.

The transient responses are obtained in the cases of a step load change, the insertion of a converter module into the system, and the removal of a converter module from the system. The resulting output voltages achieve a minimum overshoot and undershoot. Furthermore, the power factor under full load is 0.98 . Finally, the harmonic distortion at the $\mathrm{AC}$ input power source of the converter is under the IEC 61000-3-2 class A limit, and the overall efficiency is $85.97 \%$.

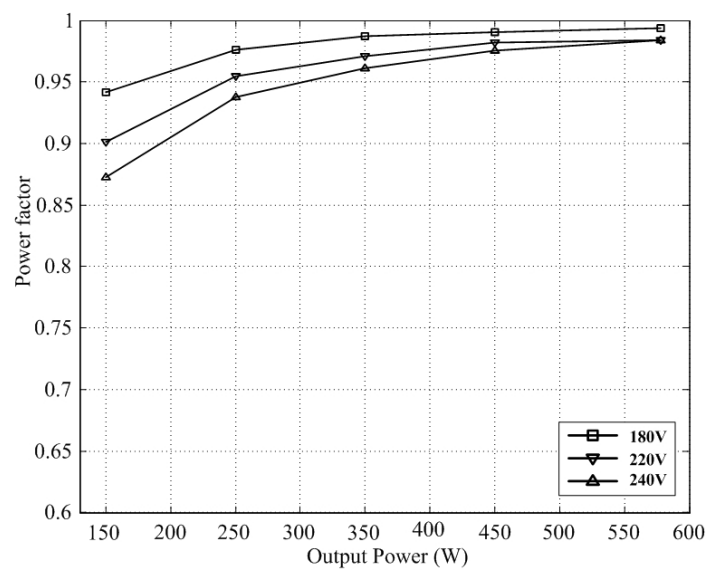

Fig. 19. The power factor versus the difference input voltage.

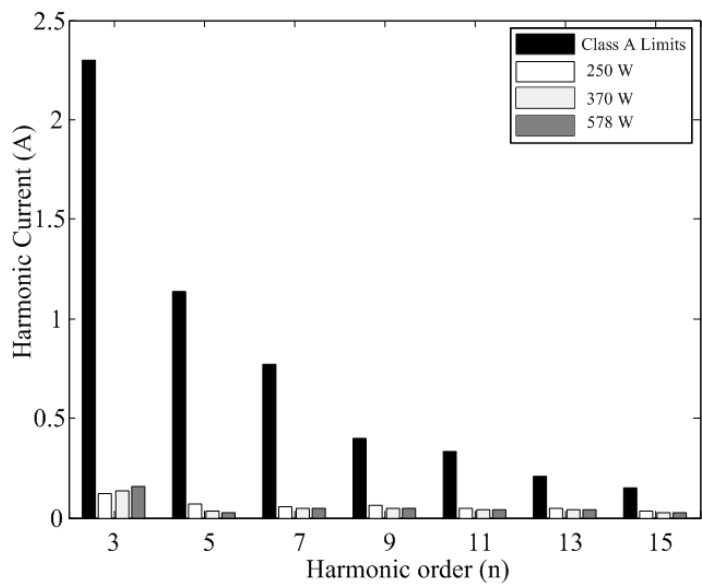

Fig. 20. The harmonic current at AC power source of the converter on the difference load 250W, 370W and 578W.

\section{ACKNOWLEDGMENT}

This work was supported by the Commission on Higher Education (CHE), of the Thailand Research Fund (TRF) under a Research Grant for New Scholars (MRG5480098), by the Rajamangala University of Technology Lanna (RMUTL), the Rajamangala University of Technology Suvarnabhumi, Nonthaburi (RMUTSB) and the King Mongkut's University of Technology North Bangkok (KMUTNB), Thailand.

\section{REFERENCES}

[1] S. Luo and I. Batarseh, "A review of distributed power systems part I: DC distributed power system," IEEE A\&E SYSTEMS MAGAZINE, Vol. 20, No. 8, pp. 5-16, Aug. 2005.

[2] S. K. Mishra, S. Zhou, W. Huang, and G. Schuellein "Design of a redundant paralleled voltage regulator module system with improved efficiency and dynamic response," in Proc. $41^{\text {st }}$ IAS Conf., pp. 2524$2528,2006$.

[3] Z. He and Y. Xing, "Distributed control for UPS modules in parallel operation with RMS voltage regulation," IEEE Trans. Ind. Electron., Vol. 55, No. 8, pp. 2860-2869, Aug. 2008.

[4] J. M. Guerrero, L. Hang, and J. Uceda, "Control of distributed uninterruptible power supply systems," IEEE Trans. Ind. Electron., Vol. 55, No. 8, pp. 2845-2859, Aug. 2008.

[5] S. Luo, Z. Ye, R.-L. Lin, and F. C. Lee, "A classification and evaluation of paralleling methods for power supply modules," in Proc. PESC, Vol. 2, pp. 901-908, 1999.

[6] J.-H. Kim, J.-G. Lim, S.-K. Chung, and Y.-J. Song, "DSP-based digital controller for multi-phase synchronous buck converters," Journal of Power Electronics, Vol. 9, No. 3, pp. 401-417, May 2009. 
[7] S.-H. Li and C.-M. Liaw, "Paralleled DSP-based soft switching-mode rectifiers with robust voltage regulation control," IEEE Trans. Power Electron., Vol. 19, No. 4, pp. 937-946, Jul. 2004.

[8] S. K. Mazumder, M. Tahir, and K. Acharya, "Master-slave currentsharing control of a parallel DC-DC converter system over an RF communication interface," IEEE Trans. Ind. Electrol., Vol. 55, No. 1, pp. 59-66, Jan. 2008.

[9] Y. Kanthaphayao, P. Wisutmetheekorn, U. Kamnarn, and V. Chunkag, "Distributed control of a parallel AC to DC converter," in Proc. ECTICON, Vol. 1, pp.68-71, 2009.

[10] J. Guo, D. Boroyevich, and S. H. Edwards, "Distributed, modular, open control architecture for power conversion systems," in Proc. PESC,, Vol. 3, pp. 2258-2263, 2004.

[11] G. Francis, R. Burgos, F. Wang, and D. Boroyevich, "A universal controller for distributed control of power electronics conversion systems," in COMPEL 'O6. IEEE Workshops on, pp. 8-14, 2006.

[12] R. V. White and D. Freeman, "Data communications issues for power system management," in Proc. APEC, pp. 1188-1199, 2007.

[13] W. Stefanutti, S. Saggini, P. Mattavelli, and M. Ghioni, "Power line communication in digitally controlled DC-DC converters using switching frequency modulation," IEEE Trans. Ind. Electorn., Vol. 55, No. 4, pp. 1509-2008, Apr. 2008.

[14] M. Popal, A. S. Popa, V. Cretu, and M. Micea, "Monitoring serial communications in microcontroller based embedded systems," in Computer Engineering and Systems, pp. 56-61, 2006.

[15] K. Kutluay, I. Cadirci, A. Yafavi, and Y. Cadirci, "Dual 8-b microcontrollers," IEEE Industry Applications Magazine, Vol. 12, pp. 59-67, Jan./Feb. 2006.

[16] K. Siri, C. Q. Lee, and T.-F. Wu, "Current distribution control for paralle1 connected converters: part I," IEEE Trans. on Aerosp. Electron. Syst., Vol. 28, No. 3, pp. 829-840, Jul. 1992.

[17] dsPIC30F6010 High-performance digital signal controllers data sheet, Microchip Technology Inc., 2004

[18] B.-R. Lin, "Analysis of neural and fuzzy-power electronic control," IEE Proc.-Sci. Meus. Technol., Vol. 144, No. 1, Jun. 1997.

[19] A. R. Ofoli and A. Rubaai, "Real-time implementation of a fuzzy logic controller for switch-mode power-stage DC-DC converter," IEEE Trans. Ind. Appl., Vol. 42, No. 6, Oct. 2006

[20] C. S. Chang and W. Fu, "Area load frequency control using fuzzy gain scheduling of PI controllers," ARTICLE Electr. Power Syst. Res., Vol. 42, No. 2, pp.145-152, Aug. 1997.

[21] S. Md. Ayob, Z. Salam, and N. A. Azli, "A new optimum design for a single input fuzzy controller applied to DC to AC converters," Journal of Power Electronics, Vol. 10, No. 3, pp. 306-312, May 2010

[22] L. Guo, J. Y. Hung, and R. M. Nelms, "Evaluation of DSP-based PID and fuzzy controllers for DC-DC converters," IEEE Trans. Ind. Electron., Vol. 56, No. 6, pp. 2237-2248, Jun. 2009.

[23] G.-B. Chung, "Investigation of PID fuzzy controller for output voltage regulation of current-doubler-rectified asymmetric half-bridge DC/DC converter," Journal of Power Electronics, Vol. 7, No. 1, pp. 21-27, Jan. 2007.
[24] S. Md. Ayob, N. A. Azli, and Z. Salam, "PWM DC-AC converter regulation using a multi-loop single input fuzzy PI controller," Journal of Power Electronics, Vol. 9, No. 1, pp. 124-131, Jan. 2009.

[25] V. Chunkag and U. Kamnarn, "Parallelling three-phase AC to DC converter using CUK rectifier modules based on power balance control technique," IET Power Electron., Vol. 3, No. 4, pp. 511-524, Jul. 2010.

[26] U. Kamnarn and V. Chunkag, "Analysis and design of a modular threephase AC-to-DC converter using CUK rectifier module with nearly unity power factor and fast dynamic response," IEEE Trans. Power Electron., Vol. 24, No. 8, Aug. 2009.

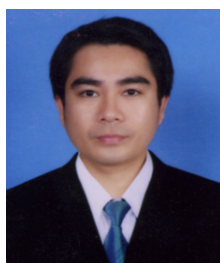

Yutthana Kanthaphayao was born in Phayao, Thai land, on August 25, 1973. He received his B.S. Ind Ed. and his M.Eng. in Electrical Engineering from King Mongkut's University of Technology Thonburi (KMUTT), Bangkok, Thailand, in 1998 and 2003, respectively. He is currently pursuing his Ph.D. at King Mongkut's University of Technology North Bangkok. His main research interests include microcontroller application of power electronic circuits, distributed power systems, and power factor correction.

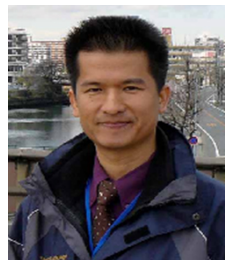

Uthen Kamnarn was born in Uttaratrid, Thailand, on March 20, 1974. He received his B.Eng. in Electrical Engineering from the Rajamangala Institute of Technology (RIT), Thanyaburi, Pathum Thani, Thailand, in 1996, his M.Eng. and Ph.D. in Electrical Engineering from King Mongkut's Institute of Technology North Bangkok (KMITNB), Bangkok, Thailand, in 2002 and 2007, respectively. He is currently a Lecturer in the Department of Electrical Engineering, Rajamangala University of Technology Lanna (RMUTL), Chiang Mai, Thailand. His main research interests include the analysis of power electronic circuits and control, harmonics on power systems, distributed power systems, power factor correction, etc.

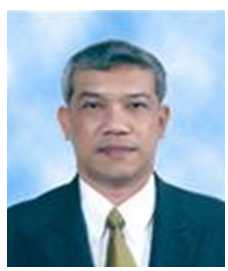

Viboon Chunkag was born in Nonthaburi, Thailand, on February 3, 1957. He received his Bs.Tech.Ed. (with Honors) in Electrical Engineering from King Mongkut's Institute of Technology North Bangkok (KMITNB), Bangkok, Thailand, in 1979, his M.S. in Electrical Engineering from Kasetsart University, Bangkok, Thailand, in 1985, and his Ph.D. from the School of Electrical and Electronic Engineering, University of Bath, Bath, U.K., in 1995. Since 1980, he has been with KMITNB, which was changed to King Mongkut's University of Technology North Bangkok (KMUTNB) in December 2007. He is currently an Associate Professor in the Department of Electrical Engineering, Faculty of Engineering, KMUTNB. His current research interests include analysis of power electronic circuits and control, rectifiers and power factor correction, power system harmonics, power switching converters, active power filters, etc. 